Association for Information Systems AIS Electronic Library (AISeL)

ICIS 1984 Proceedings

International Conference on Information Systems

1984

\title{
The Information System as a Competitive Weapon
}

Blake Ives

Dartmouth College

Gerard R. Learmonth

Dartmouth College

Follow this and additional works at: http://aisel.aisnet.org/icis1984

\section{Recommended Citation}

Ives, Blake and Learmonth, Gerard R., "The Information System as a Competitive Weapon" (1984). ICIS 1984 Proceedings. 3. http://aisel.aisnet.org/icis1984/3

This material is brought to you by the International Conference on Information Systems (ICIS) at AIS Electronic Library (AISeL). It has been accepted for inclusion in ICIS 1984 Proceedings by an authorized administrator of AIS Electronic Library (AISeL). For more information, please contact elibrary@aisnet.org. 


\title{
The Information System as a Competitive Weapon
}

\author{
Blake Ives \\ Gerard P. Learmonth \\ Dartmouth College \\ Nathan Smith Building
}

\begin{abstract}
Long considered backoffice support tools, information systems have become strategic competitive weapons. In the airline, travel services, financial services, and distribution industries, for example, information systems have become strategic competitive weapons. Information systems have been used to produce new products or to substantially modify old one. Frequently, these systems increase the customer's "switching costs," and thereby increase dependence on the supplier. This phenomenon has been discussed by several researchers, and disparate descriptive models proposed. A new model, the Customer Resource Life Cycle Model, provides a powerful descriptive capability and potential as a mechanism for generating strategic applications. The model assumes competitive advantages can be obtained by supporting a customer's resource life cycle via information systems technologies. Numerous applications illustrate the descriptive power of the model.
\end{abstract}

The considerable attention recently paid to using information systems as competitive weapons can be attributed to several factors, inciuding the unrelenting decline of the cost of information technologies; structural changes in the economy wrought by the recent economic decline and subsequent recovery; and, perhaps most importantly, by the deregulation of many industries - particularly airlines and finaricial services. Companies, once shackled by regulatory agencies, have moved quickly to replace limited, but well understood product lines with a varied, ever changing menu of new products and services. Information systems have played a critical role in managing this diversity.

Information systems are beginning to distinguish successful firms from their competitors. And they are doing it where it counts - in the market place. Information systems are emerging from the back office and making their way to the corporate boardroom.

Recent studies (reviewed in the paper) describe how information systems can be exploited to an organization's competitive advantage and present descriptive models for classifying successful strategic applications or evaluating the potential of proposed applications. We present a new model for describing strategic information systems, a model with a prescriptive character. We expect that the model will foster and encourage the discovery of new opportunities for the successful application of information system technologies. We have populated the model with several dozen examples of such information system applications to enhance the prescriptive capabilities.

\section{The Product/Resource Life Cycle}

It is well known that an organization's products or services go through a fairly well-defined life cycle. Within IBM's Business Systems Planning process, for instance, four stages are proposed for the life cycle of both products/services and supporting resources:

*This paper is forthcoming in Communications of the ACM. 
- Requirements, planning, measurement, and control

- Acquisition or implementation

- Stewardship

- Retirement or disposition

\section{The Customer's Resource Life Cycle}

The products an organization provides its customers are, from the customers perspective, supporting resources. To acquire them the customer goes through a resource life cycle, a life cycle frequently requiring a considerable investment of time and effort to manage. If the supplier can assist the customer in managing this life cycle, then the supplier, through higher quality customer service, may differentiate itself from its competitors. Simultaneously, the supplier has introduced customer switching costs.

The customer's resource life cycle (CRLC) can frequently be supported through the application of supplier-provided IST. Frequently, transactions with customers are sufficiently homogeneous to economically justify the supplier developing support systems which the customer can't afford.

The four-stage IBM model is a helpful starting point, but provides a rather rough cut at the CRLC. A more detailed breakdown significantly improves the model's utility. Burnstine has proposed an eleven-stage resource life cycle model and we have extended it by two more stages (see Exhibit). Any of these thirteen-stages may be amenable to support from supplierdeveloped strategic information systems.

The CRLC model provides a tool for seeking out new competitive applications. The 13 stages focus the search, while the dozens of examples included in the paper provide analogies that serve as a catalyst to creative thought.

Competitive information systems have already shown themselves to be of strategic importance in several industries and their influence is being felt in many others. The importance of these systems has been well documented in the literature, and several authors have provided criteria useful in evaluating the utility of both existing and potential applications. The CRLC model goes a step further by providing a tool to assist in identifying such systems. Because it focuses on customer service, the model is of primary use for building in customer switching costs and differentiating a product or service. 


\section{IBM Stage Extended Model $\quad$ Description}

1. Requirements 1. Establish Requirements

2. Specify

How much of the resource is required?

What are the resources attributes?

2. Acquisition

3. Select Source

Where will we buy it from?

4. Order

5. Authorize*

6. Acquire*

7. Test and Accept

Order a quantity from the supplier.

Authorize monies to be spent for the resource.

Take possession of the resource.

Ensure it meets specifications.

3. Stewardship

8. Integrate

9. Monitor

10. Upgrade

11. Maintain

4. Retirement

12. Transfer or Dispose

13. Account for and Pay for

Add to existing inventory.

Control access and use of the resource.

Upgrade resource if conditions change.

Repair resource if necessary.

Move, return, or dispose of the inventory as necessary.

Monitor where and how much is spent on the resource.

* Not included in Burnstine's (Burn, 1980) original list, but subsumed instead under Order and Test \& Accept.

EXHIBIT: The Four and Thirteen Stage Resource Life Cycles (Burn, 1980, IBM, 1981) 